\section{A case of epileptic seizure due to lidocaine local anesthesia.}

\author{
Ibrahim Karagoz ${ }^{1} \&$ Kubra Turkoglu. ${ }^{1}$
}

Abstract: Lidocaine is an amide-structured local anesthetic commonly used in practice in anesthesiology. Because of its rapid onset, it is frequently used in topical and infiltration anesthesia, regional blocks, regional intravenous anesthesia (RIVA) and general anesthesia to suppress hemodynamic responses to intubation, as well as some cardiac arrhythmias and epileptic seizures. Here, we present a case with seizures and impaired consciousness following iv lidocaine treatment during sedoanalgesia without a history of epilepsy. A thirty-seven-year-old female patient, who was scheduled for a cervical biopsy operation in the Gynecology and Obstetrics clinic, developed a loss of consciousness due to lidocaine with tonic-clonic epileptic seizures during treatment with sedoanalgesia. The patient was intubated with $2 \mathrm{mg}$ midazolam, $200 \mathrm{mg}$ propofol and $50 \mathrm{mg}$ rocuronium intravenously, while oxygen was provided by mask at 6 liters / min. Anesthesia was maintained with 4 lt $/ \min 50 \%$ oxygen and $50 \%$ air mixture and $2 \%$ sevoflurane. There were signs of respiratory acidosis in the blood gas analysis. She was intubated for half an hour by a mechanical ventilator. The operation was canceled. In blood gas monitoring the values were within normal limits. Sugammadex was applied by the gynecology and obstetrics department. In all cases where local anesthetic is planned, necessary precautions should be taken to cope with rare complications.

Keywords: lidocaine; sedoanalgesia; epileptic seizure; respiratory acidosis.

\section{INTRODUCTION}

Lidocaine is an amide-structured local anesthetic commonly used in anesthesia practice. Because of its rapid onset, it is frequently used for topical and infiltration anesthesia, regional blocks, regional intravenous anesthesia (RIVA) and general anesthesia, in order to suppress hemodynamic response to intubation and in the treatment of some cardiac arrhythmias and epileptic seizures (Bigger \& Hoffman, 1990; Du et al., 2011). It is usually used in a dose of $1-1.5 \mathrm{mg} / \mathrm{kg}$ intravenously before intubation to suppress the hemodynamic response for intubation purposes. As with all local anesthetics, signs of toxicity occur in the case of overdose with lidocaine. Local anesthetic toxicity, central nervous system (CNS) findings, such as numbness in the tongue, visual disturbance, muscle contraction and blurred consciousness can be seen and the most serious symptoms include convulsion, coma, respiratory arrest and cardiovascular depression (Benjamin et al. 1998; Miller, 1994).

In the present article, we aim to present a case that developed an epileptic seizure after lidocaine sedoanalgesia.

\section{CASE PRESENTATION}

A 37-year-old woman weighing $80 \mathrm{~kg}$ was planned for cervical biopsy in the Gynecology and Obstetrics clinic. Her preoperative evaluation and family
INT J MED SURG SCI
Affiliation: ${ }^{1}$ Abant lzzet Baysal University Hospital, Department of Anesthesiology and Reanimation, Bolu, Turkey.

Corresponding: : Ibrahim Karagoz, M.D. Abant lzzet Baysal University Hospital, Department of Anesthesiology and Reanimation, Golkoy, 14280, Bolu, Turkey. Phone: +903742534656. Fax: +903742534615.

E-mail: dr.ikar@hotmail.com.

$\begin{array}{ll}\text { Receipt: } & 12 / 07 / 2018 \\ \text { Revised: } & 01 / 07 / 2019 \\ \text { Acceptance: } & 01 / 14 / 2019 \\ \text { Online: } & 01 / 25 / 2019\end{array}$

Conflict of interests: None.

Ethics approval: None.

Funding: None.

Authors' contributions: All authors carried out the entire case report.

Acknowledgements: None.

doi: $10.32457 /$ ijmss.2018.028. 
or individual history were not relevant. Physical examination was normal. Laboratory studies including hemogram, routine biochemistry, PA chest X-ray and ECG were normal. According to the American Society of Anesthesiologists (ASA), ASA I risk was referred to the patient and sedoanalgesia was planned by our clinic.

No sedative premedication was applied in the operating room. Routine monitoring, ECG, peripheral oxygen saturation (Sp02), pulse and noninvasive blood pressure (NIBP) were applied. Sp02 was $100 \%$, heart rate was 110 beats / min and blood pressure was 109/59 mmHg. 0.9\% isotonic $\mathrm{NaCl}$ solution with an intravenous $20 \mathrm{G}$ cannula from the right brachial region was started at $120 \mathrm{cc} / \mathrm{h} .1$ $\mathrm{mg} / \mathrm{kg}$ dose of $80 \mathrm{mg}$ lidocaine (2\% 4 cc Aritmal) was given by an intravenous route in 10 seconds. Approximately 2-3 seconds after the injection, the patient suddenly stated that she was sleepy, meanwhile, her eyes fixed upwards; then, she lost consciousness and tonic-clonic contractile convulsions developed in her whole body.

Ventilation was provided with 6 It / min oxygen by mask and the patient was intubated after $2 \mathrm{mg}$ midazolam, $200 \mathrm{mg}$ propofol and $50 \mathrm{mg}$ rocuronium. After intubation, ETC02 was measured to be $78 \mathrm{mmHg}$, NIBP 122/62 mm / Hg, pulse 160 beats / min, Sp02 99\%, fever 37.6 C. Anesthesia was maintained with 4 It / $\min 50 \%$ oxygen and $50 \%$ air mixture and $2 \%$ sevoflurane. Mechanical ventilation adjustment set on tidal volume $8 \mathrm{ml} / \mathrm{kg}$, respiratory frequency $14 / \min$, PEEP $5 \mathrm{~cm} \mathrm{H20}$. Blood gas was measured from the radial artery and revealed $\mathrm{pH}$ : 7.00, Sp02 95.2\%, PaC02 48 mmHg, Na 145.9 mmol / L, PaO2 111 mmHg, K 1.95 mmol / L, HCO3 12.6 mmol, Ca ++ $0.32 \mathrm{mmol} / \mathrm{L}, \mathrm{BE}-18.1 \mathrm{mmol} / \mathrm{L}$, glucose $102 \mathrm{mg} / \mathrm{dl}$. The lactate was $8.2 \mathrm{mmol} / \mathrm{L}, \mathrm{Hb}$ was $12.4 \mathrm{~g} / \mathrm{dL}$. The case was diagnosed with respiratory acidosis. For the treatment of local anesthetic substance toxicity, $0.25 \mathrm{ml} / \mathrm{kg} / \mathrm{min}$ infusion treatment was started after $1.5 \mathrm{~mL} / \mathrm{kg}$ bolus dose of $20 \%$ lipid emulsion. She was intubated for half an hour in a mechanical ventilator. The operation was canceled. In the blood gas control test, the values were within normal limits. Sugammadex was applied and the patient was followed for one hour in the recovery unit. The patient's physical examination and laboratory values were normal, and she was sent to the gynecology department with the suggestion of a neurology consultation.

Her neurological examination, cranial MRI and EEG were normal, and she was operated three days later. Premedication was achieved with $2 \mathrm{mg}$ midazolam. Then, 50 mcg fentanyl and $160 \mathrm{mg}$ propofol were applied, LMA and surgical operation (cervical biopsy) was performed under general anesthesia. After the procedure, the patient was awakened smoothly and transferred to gynecology ward.

\section{DISCUSSION}

The seizure during sedoanalgesia was associated with lidocaine toxicity. Changes in consciousness ranging from confusion to coma have been reported due to local or systemic administration of lidocaine. Although lidocaine is a reliable agent, side effects of overdose can often be seen due to its wide area of use. Vertigo, numbness in the tongue and around the mouth, ataxia, agitation, convulsion, respiratory depression, coma and cardiovascular system collapse can be seen (Bigger \& Hoffman, 1990; Morgan et al., 2004; Benjamin et al., 1998; Miller, 1994).

Although local anesthetic drugs have been known to trigger seizures in a dose-dependent manner for many years, there is insufficient information about the central mechanism of action. The risk of seizures is higher with procaine and lidocaine has the lowest risk (Usubiaga et al., 1996). Local anesthetics are soluble in fat and can easily pass through the blood brain barrier and act on cell membranes, neurotransmitter functions and neuronal excitability. Cerebral inhibitor blocks neurons and leads to excitation of the central nervous system. Lidocaine has a concentration-dependent effect on the seizure. Although it has an anticonvulsant effect at low doses, it may cause excitability and seizure at doses above $5 \mu \mathrm{g} / \mathrm{mL}$ (DeToledo, 2000; Dorf et al., 2006; DeToledo et al., 2002; Garfield \& Gugino, 1987). In our case, excitability and seizures were observed at the treatment dose.

Systemic toxicity of local anesthetics is affected by various factors, such as dose of drug, rate of administration, presence of concomitant disease and age (Miller, 1994). Systemic toxicity may occur even in lower blood concentrations of the local anesthetic in alpha-1-acid glycoprotein and albumin deficiencies (Berde \& Strichartz, 2000). No pathology was found neither in the preoperative 
evaluation of the presented case nor in the postoperative examinations. Blood protein values were also normal. The dose of local anesthetic administered was within the recommended dose limits for the intravenous route.

\section{CONCLUSION}

The development of convulsions after lidocaine administration at safe dose limits suggests that individual factors may also be important in response to the drug. Adherence to the standards in the treatments, giving appropriate doses to weight and age, choosing the appropriate techniques, even during the use of local anesthetics one should be aware that serious side effects may occur even in most experienced hands. Therefore, in all cases where local anesthetic is planned, measures should be made available to cope with rare complications.

\section{REFERENCES}

Benjamin G, Wildsmith CAW, Wildsmith JAW. Clinical pharmacology of local anesthetic agents. In: Cousins MJ, Bridenbaugh PO (eds). Neural blockade in clinical anesthesia and management of pain. 3rd ed. Philadelphia: Lippincott Raven Press; 1998.

Berde CB, Strichartz GR. Local anesthetics. In: Miller RD (ed). Anesthesia. 5th ed. Philadelphia: Churchill Livingstone Inc; 2000.

Bigger JT, Hoffman DF. Antiarrhythmic drugs. In: Gillman AG, Rall TW, Nies AS. Goodman \& Gilman's: The pharmacological basis of therapeutics. 8th ed. New York: Pergamon Press;1990.

DeToledo JC. Lidocaine and seizures. Ther Drug Monit. 2000;22(3):320-2.

DeToledo JC, Minagar A, Lowe MR. Lidocaineinduced seizures in patients with history of epilepsy: effect of antiepileptic drugs. Anesthesiology. 2002;97(3):737-9.

Dorf E, Kuntz AF, Kelsey J, Holstege CP. Lidocaineinduced altered mental status and seizure after hematoma block. J Emerg Med. 2006;31(3):251-3.

Du G, Chen X, Todorovic MS, Shu S, Kapur J, Bayliss DA. TASK Channel Deletion Reduces Sensitivity to Local Anestheticinduced Seizures. Anesthesiology 2011;115(5):1003-11.

Garfield JM, Gugino L. Central effects of local anesthetic agents. In: Strichartz GR, editor. Local anesthetics handbook of experimental pharmacology. 1st ed. Berlin-Heidelberg: Springer-Verlag; 1987.

Miller RD. Anesthesia. Philadelphia: Churchill Livingstone. Local anesthetics. 1994.

Morgan GE, Mikhail MS, Murray MJ. Clinical Anesthesiology. 4th ed. New York: Lange Medical Books/ McGraw-Hill; 2004.
Usubiaga JE, Wikinski J, Ferrero R, Usubiaga LE, Wikinski R. Local anesthetic-induced convulsions in man--an electroencephalographic study. Anesth Analg 1966;45(5):61120. 